\title{
Histological study of effects of colloidal 90 yttrium on knee joint tissues of rabbits
}

\author{
K. PAVELKA, W. MEIER-RUGE, W. MÜLlER, AND R. FRIDRICH \\ From the Rheumatological University Clinic of Basle, Institute for Basic Medical Research; Laboratory of \\ Experimental Pathology, Sandoz Ltd., Basle; and Department of Nuclear Medicine of the Radiological \\ University Institute, Basle, Switzerland
}

\begin{abstract}
Pavelka, K., Meier-Ruge, W., Müller, W., and Fridrich, R. (1975). Annals of the Rheumatic Diseases, 34, 64. Histological study of effects of colloidal 90 yttrium on knee joint tissues of rabbits. The administration of $0 \cdot 2-0.4 \mathrm{mCi} 90$ yttrium $\left({ }^{90} \mathrm{Y}\right)$ into a normal rabbit knee joint fails to induce medical synovectomy and results in the proliferation of the synovialis. The synovial mesothelium shows early radiation damage but subsequently follows a restitution of the whole. Later (within 4 to 16 weeks) an extensive fibrosis of the stratum synovialis develops, as well as an occlusion and sclerosis of smaller synovial vessels and capillaries. These changes explain the beneficial therapeutic effect of ${ }^{90} \mathrm{Y}$ in a chronic inflammatory joint effusion. After irradiation the joint cartilage shows an increased cellular proliferation of the superficial tangential cells and in the vicinity of the cruciate ligaments small foci of degenerated cartilage are present. The overall pattern of a joint treated with intra-articular ${ }^{90} \mathrm{Y}$ corresponds to the histological pattern encountered regularly in joints of older people. Changes of the cartilage after the ${ }^{90} \mathrm{Y}$ radiation could represent a factor predisposing the treated joint to a subsequent development of osteoarthrosis.
\end{abstract}

The synovitis associated with rheumatoid arthritis accounts for most of the pathological joint changes and the immunocompetent cells in the synovium markedly influence the immune process which occurs in this disease. As a result of this, early synovectomy has been generally accepted and today represents an inherent part of the treatment of rheumatoid arthritis. Since this major surgical procedure, however, is associated with an uncertain prognosis, prolonged convalescence, and postoperative rehabilitation, rheumatologists have attempted to eliminate the synovial membrane by a nonsurgical procedure termed by French authors 'synoviorthesis'. To achieve this, chemical and radioactive agents as well as steroids have been utilized.

The first radioisotope used for radiation synovectomy was colloidal gold $\left({ }^{198} \mathrm{Au}\right)$. The advantages of this agent have been reported (Ansell, Crook, Mallard, and Bywaters, 1963; Grahame, Ramsey, and Scott, 1970; Virkkunen, Krusius, and Heiskanen, 1967; Webb, Lowe, and Bluestone, 1969), but a major disadvantage is the leakage of ${ }^{198} \mathrm{Au}$ from the joint to the regional lymph nodes, blood stream, and the reticuloendothelial system where the dose of radiation may be unacceptably high. Ansell and others (1963) recommended treatment with radioactive ${ }^{90} \mathrm{Y}$ for synoviorthesis, and this was tested in a larger clinical series by Delbarre, Cayla, Menkes, Aignan, Rancayrol, and Ingrand (1968). These two radioisotopes have an identical half-life of 2.7 days and this makes them convenient for the treatment of rheumatoid arthritis. While the depth of penetration of ${ }^{198} \mathrm{Au}$ radiation is only $1 \mathrm{~mm},{ }^{90} \mathrm{Y}$ penetrates an average $5 \mathrm{~mm}$ and is thus theoretically more suitable for synovial ablation in a large joint with changes of hypertrophic synovitis.

The uptake of ${ }^{90} \mathrm{Y}$ by the synovial membrane was studied in animal experiments by Webb and others (1969) who injected $0 \cdot 1 \mathrm{mCi}{ }^{90} \mathrm{Y}$ into the knee joint of normal rabbits and of rabbits with adjuvant arthritis. Percutaneous measurements showed that $\sigma$ almost all the isotope was present in the joint $24 \mathrm{~N}$ hours after intra-articular administration and auto- N radiography showed a homogeneous distribution of ${ }^{90} \mathrm{Y}$ throughout the synovial membrane. Isomäki, Inoue, and Oka (1972) confirmed the radiographical findings.

Some promising results of the clinical use of ${ }^{90} Y$ (Delbarre and others, 1968; Oka, Rekonen, Ruotsi, and Seppälä, 1971; Wiedermann, Vykydal, 
Pěgřímová, Pračke, and Valach, 1969) have been confirmed in our own clinical series (Müller, Fridrich, and Pavelka, 1974). One of the crucial problems of a radiation synovectomy is that of further damage to the articular cartilage. Therefore, in the present study we have investigated histologically the effects of ${ }^{90} \mathrm{Y}$ on normal rabbit knee joint tissues.

\section{Methods}

Twelve rabbits approximately 6 months old and of a mean weight of $2500 \mathrm{~g}$ were used in our experiments. After intraperitoneal anaesthesia with $0.5 \mathrm{ml} / \mathrm{kg}$ body weight of Numal $^{\circledR}$ (Roche), injections of $0.1 \mathrm{ml}$ sterile suspension containing $0.2-0.4 \mathrm{mCi}$ colloidal ${ }^{90} \mathrm{Y}$ silicate (Radiochemical Centre, Amersham, England) with particle size $100 \mathrm{~nm}$ were injected via an anterior subpatellar approach into the left knee joint of each rabbit. $X$-ray films and arthrography were used to ensure that injection was into the true joint space. Six rabbits received a dose of $0.2 \mathrm{mCi}$; the other 6 received $0.4 \mathrm{mCi}$. Two animals, one from each dosage group, were sacrificed after 2,4 , 8 , and 16 weeks, and 4 animals were kept alive for longterm follow-up. Knee joints of the sacrificed rabbits were dissected and fixed in Bouin solution. The right knee joint which was not treated with ${ }^{90} \mathrm{Y}$ served as control. The joints were marked with code numbers and studied blind by the histologist. The fixing Bouin solution was changed twice in one week. After 4 days of fixation the joints were sectioned in order to obtain a central crosssection containing all articular tissues including the meniscus. The sections were again fixed for 3 days in Bouin solution, then dehydrated for 4 days in methanol, and without decalcification embedded under vacuum in methylacrylate (Burkhardt, 1966a, b) (solution $100 \mathrm{ml}$ nonstable methylacrylate, $3.5 \mathrm{~g}$ benzoyl-peroxide, and $25 \mathrm{ml}$ plastoid $\mathrm{N}$ ). The methylacrylate was repeatedly changed over a 3-day period before the mixture was allowed to polymerize at $37^{\circ} \mathrm{C}$ (Burkhardt, 1966a, b; Gardner, 1972; Vittali, 1970). Blocks were cut with a cut-all Zeiss microtome to give $4 \mu \mathrm{m}$ thick sections, which were mounted on a slide with a layer of gelatine, pressed on with a small roller over a cigarette paper, and dried at $40^{\circ} \mathrm{C}$. Sections were then cleared with benzene, rehydrated in a descending series of methyl alcohols, and finally stained with the usual methods for paraffin sections, i.e. Jaune solide, Giemsa, metachromatic staining by toluidin blue, and azur-eosin according to Nocht-Maximov.

\section{Results}

Within 2 weeks after the injection of colloidal ${ }^{90} \mathrm{Y}$ silicate into the knee joint, the synovial membrane showed round cell infiltrates (Fig. 1) consisting of plasma cells, histiocytes, fibroblasts, and isolated deposits of fibrin. Synovial villi contained a serous effusion with relatively few leucocytes and round cells. A striking feature was the thrombotic occlusion of numerous capillaries within the synovial villi. These were especially obvious in the region of the cruciate ligaments. Some capillaries were recanalized (Fig. 2). The mesothelium of the synovia showed an intense proliferation. On the tibial side of the joint cartilage slight defects of tangential cells could be observed. After the injection of $0.4 \mathrm{mCi}^{90} \mathrm{Y}$, discrete foci of degenerate joint cartilage appeared in the tangential layer.

After 4 weeks, most of the inflammatory and reactive changes had subsided, although compared to the controls (Fig. 3b) the synovial mesothelium still showed a higher cellularity and the stratum synoviale still showed a definite increase of fibroblasts and fibrocytes (Fig. 3a), particularly in synovial villi and also in the joint capsule. Near small veins an increase of fibrocytes and collagen fibres was seen.

At 8 weeks after injection of ${ }^{90} \mathrm{Y}$ the cellular infiltration of the subsynovium was markedly decreased. At this time a conspicuous, mostly patchy,

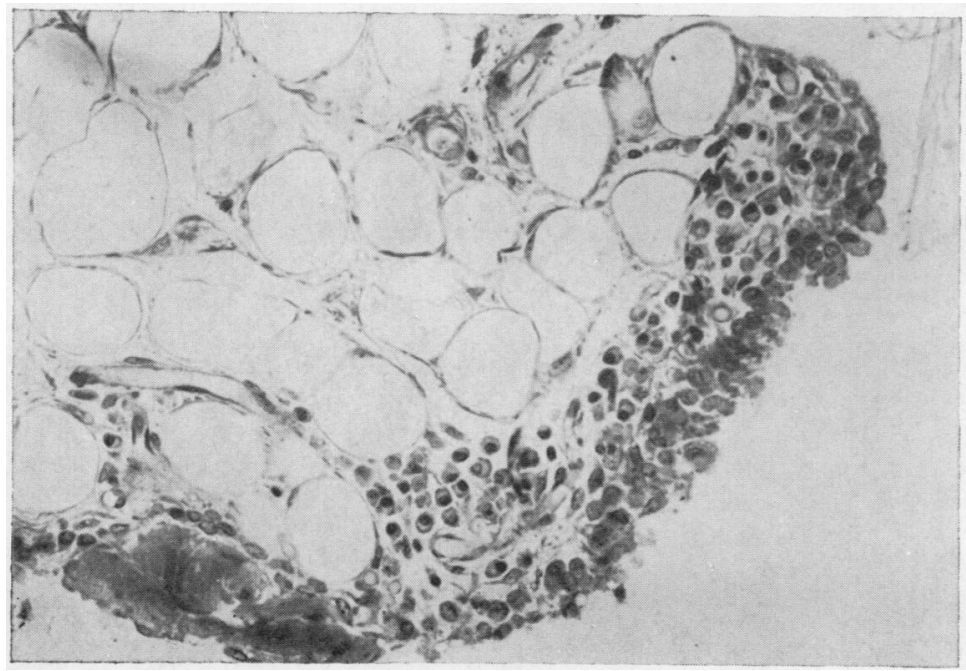

FIG. 1 Synovium of knee joint with fibrin deposition, infiltration of the subsynovial layer with histiocytes, plasma cells, and fibroblasts; 2 weeks after injection of ${ }^{90} Y$. Jaune solide. $\times 217$ 


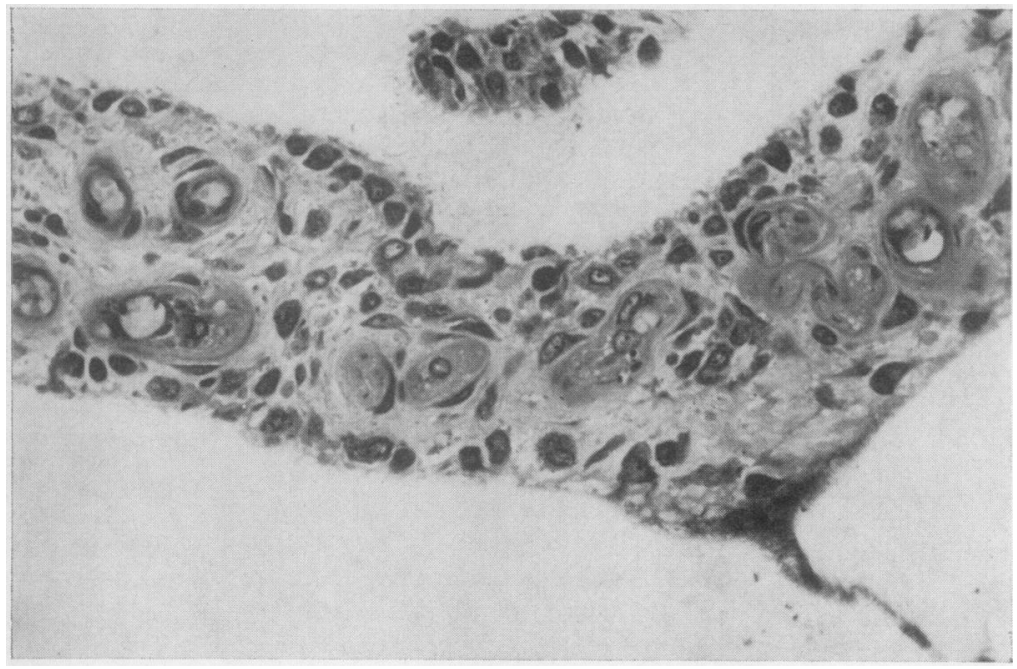

FIG. 2 Synovial villus in the region of the cruciate ligaments with increased histiocytes, $\vec{\nabla}$ thrombosis of venous vessels, and recanalized vessels; 2 \&ै weeks after injection of ${ }^{90} \mathrm{Y}$ Jaune solide. $\times 288$
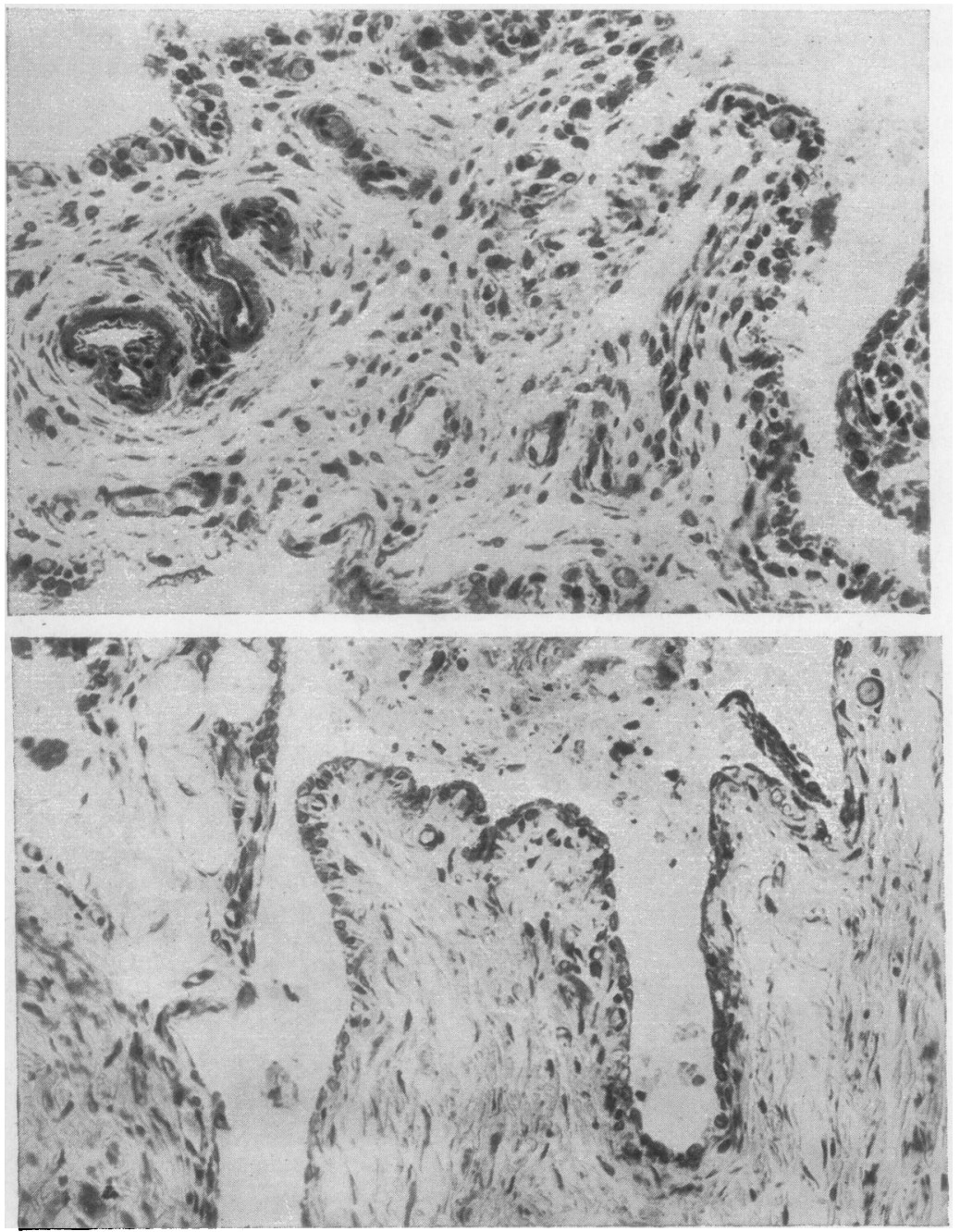

$3(a)$

$3(b)$

FIG. 3 Knee joint capsule. స్ (a) Increase of fibroblasts, $\bar{O}$ fibrocytes, and collagen fibres surrounding vessels 4 weeks after injection of ${ }^{90} Y$. (b) Control situation. Jaune solide. $\times 186$ 


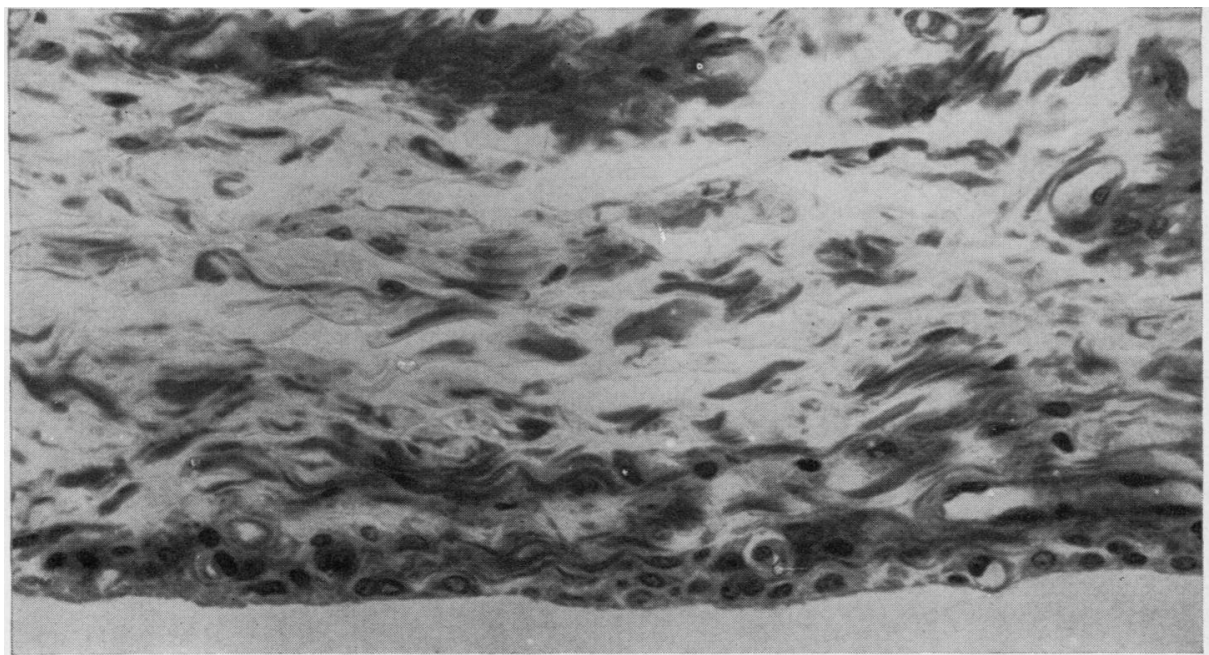

(a)

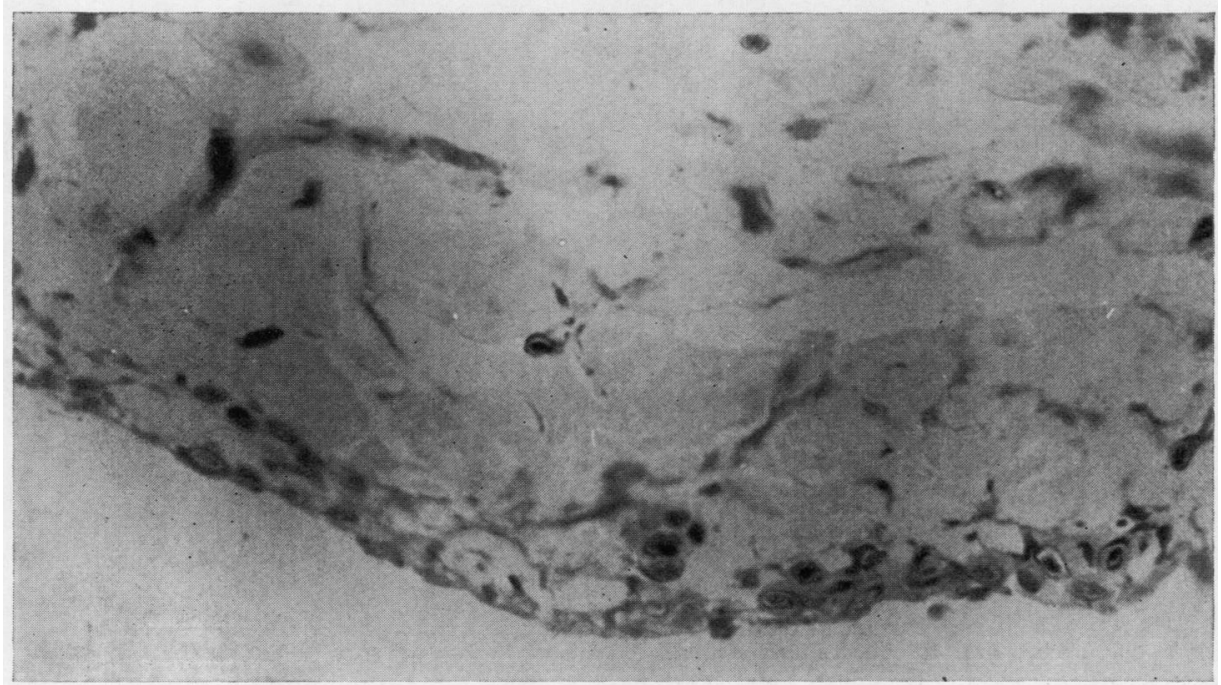

(b)

FIG. 4 (a) Sclerosis of the synovium and regeneration of the mesothelium 16 weeks after injection of ${ }^{90} Y$ into the knee joint. Fibrosis of subsynovial vessels. (b) Normal appearance of the synovium of a control. Jaune solide. $\times 360$

formation of collagen occurred within the synovial membrane and consisted partly of epithelialization of fibroblasts and the synovial mesothelium. Fibrotic vessels and an increase of interstitial fibrous tissue could be seen between fat cells of the joint capsule. Synovial mesothelium had again mostly regenerated. After higher doses of ${ }^{90} \mathrm{Y}$, the cartilage of the tibial part of the joint contained single degenerative foci with destruction of the tangential layer of cartilage in the vicinity of the cruciate ligaments.

After 16 weeks, both sclerosis of the subsynovium and regeneration of the mesothelium were even more marked than after 8 weeks (Fig. 4a). In control joints the subsynovium consisted of loose highly vascularized connective tissues. In yttrium-treated joints numerous vessels in the synovial membrane had developed in newly formed collagen. Thus the pattern of the subsynovium differed in its appearance from controls (Fig. 4b). The tangential layer of the cartilage in joints treated with ${ }^{90} \mathrm{Y}$ had an unconspicuous structure, although we observed in addition to older healed foci, fresh foci of degenerate cartilage with a histocytic reaction (Fig. 5). These were present in the vicinity of the cruciate ligaments. 


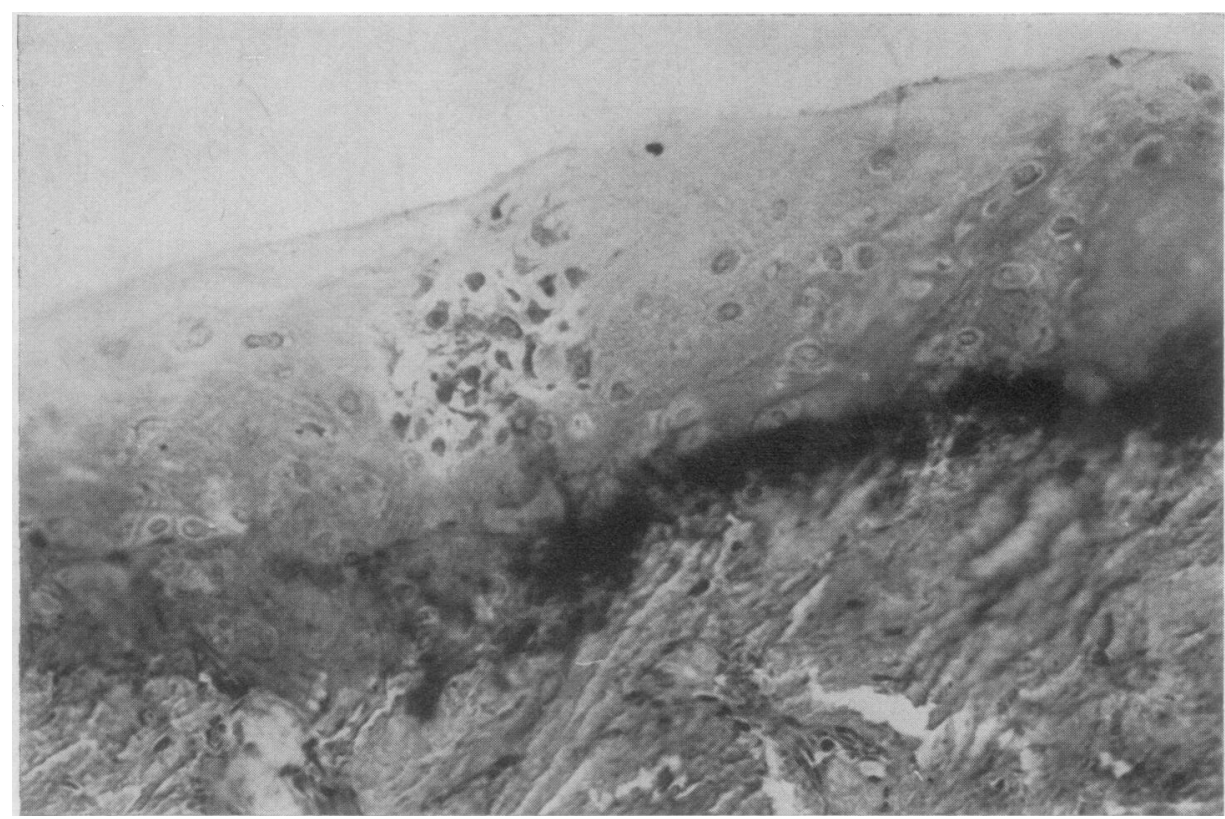

FIG. 516 weeks after ${ }^{90} Y$ injection, foci of newly degenerated cartilage in the vicinity of the cruciate ligaments of the knee joint. Jaune solide. $\times 230$

The comparison of the articular patterns after $0.2 \mathrm{mCi}$ and $0.4 \mathrm{mCi}^{90}{ }^{90}$ failed to disclose any essential differences other than these already mentioned.

\section{Discussion}

Intra-articular injection of ${ }^{90} \mathrm{Y}$ into rabbit knee joints resulted in a mild reactive inflammation which, however, subsided rapidly. It was characterized by an increase of fibroblasts and by fibrotic changes in the subsynovium and synovial vessels. This process was probably enhanced by thrombotic occlusions of smaller vessels and capillaries. The initial damage of the synovial mesothelium subsided and, contrary to expectation, no synovectomy or synoviorthesis took place. Instead, synovial proliferation was observed.

One of the adverse side effects of ${ }^{90} \mathrm{Y}$ consisted of slight diffuse changes in articular cartilage, especially in the tangential layer of the cartilage near the tibia. Where the cartilage layer was very thin (in the neighbourhood of the cruciate ligaments) foci of degeneration were seen. Such localization of these foci could possibly be explained by an increased accumulation of the injected radioisotope in the folds of the cruciate ligaments on the one hand, or by the thinness of the layer of cartilage on the other. There is a further possible reason-namely speciesspecific characteristics of the rabbit cartilage. The other changes seen in the cartilage were probably as a result of regeneration. Thus, it can be said that the adverse side effect of ${ }^{90} \mathrm{Y}$ on the cartilage is much less pronounced than its major effect on the synovial membrane.

The rabbit knee joint treated with ${ }^{90} \mathrm{Y}$ can be said to resemble the human joint in older patients since cartilage changes and a fibrosis of the stroma of synovial villi and of their vessels may be seen in both (Bollet, 1969; Lang, 1957; Ruckes and Schuckmann, 1962; Soeur, 1949). However, treatment with intra-articular ${ }^{90} \mathrm{Y}$ also results in an occlusion of the capillaries of the synovial membrane and in fibrosis of the subsynovial layer, hence reducing the filtration and resorption rate of the synovial fluid. This is a possible explanation for the favourable therapeutic effects of ${ }^{90} \mathrm{Y}$ in a chronic inflammatory joint effusion.

Conversely, it might be assumed that the reduced filtration and resorption of synovial fluid increases the vulnerability of the joint to mechanical and metabolic strain and thus predisposes the knee joint to arthrosis. The reduced metabolic rate might result in degenerative changes of the joint cartilage only after a prolonged period, a long time after synovial proliferation produced by ${ }^{90} \mathrm{Y}$ radiation had subsided. However, it seems to be important that the proliferation of chondrocytes in the tangential layer of the cartilage subsides without any sequelae provided that undue strain of the joint is avoided during 
the critical period of time (Ruckes and Reissland, 1960). Möttönen, Pantio, and Nevalainen (1970) have studied the histological pattern of the rabbit knee joint after the administration of osmium tetroxide. The changes occurring after the administration of osmium tetroxide were characterized by a rapid necrosis of the synovial mesothelium, by foreign body granulomas deep within the subsynovium followed within 5 weeks by fibrosis. These changes result in a markedly thickened and rigid synovium. We consider the treatment with ${ }^{90} \mathrm{Y}$ as less traumatic than the use of osmium.

Our experimental study confirms the observation of Delbarre and others (1968) that the treatment of a joint with ${ }^{90} \mathrm{Y}$ does not result in the destruction of the synovial membrane. Thus, this method does not represent a radiation synovectomy. However, it was possible to provide an explanation of the beneficial effects of this treatment on a chronic inflammatory joint effusion.

\section{References}

Ansell, B. M., Crook, A., Mallard, J. R., and Bywaters, G. L. E. (1963) Ann. rheum. Dis., 22, 435 (Evaluation of intra-articular colloidal gold $\mathrm{Au} 198$ in the treatment of persistent knee effusions)

Bollet, A. J. (1969) Arthr. and Rheum., 12, 152 (An essay on the biology of osteoarthritis)

BURKHARDT, R. (1966a) Blut, 13, 337 (Präparative Voraussetzungen zur klinischen Histologie des menschlichen Knochenmarkes)-1. Mitteilung

_ (1966b) Ibid., 14, 30 (Präparative Voraussetzungen zur klinischen Histologie des menschlichen Knochenmarkes. -2. Mitteilung)

Delbarre, F., Cayla, J., Menkes, C., Aignan, M., Rancayrol, J.-C., and Ingrand, J. (1968) Presse Méd., 76, 1045 (La synoviorthèse par les radio-isotopes)

Gardner, D. L. (1972) in 'The Pathology of Rheumatoid Arthritis'. Arnold, London

Grahame, R., Ramsey, N. W., AND Scott, J. T. (1970) Ann. rheum. Dis., 29, 159 (Radioactive colloidal gold in chronic knee effusions with Baker's cyst formation)

IsomäKI, A. M., INOUE, H., AND OKA, M. (1972) Scand. J. Rheum., 1, 53 (Uptake of ${ }^{90}$ Y resin colloid by synovial fluid cells and synovial membrane in rheumatoid arthritis)

LANG, J. (1957) Morph.J., 98, 1957 (Die Gelenkinnenhaut, ihre Aufbau-und Abbauvirgänge)

Möttönen, M., Pantio, M., AND Nevalainen, T. (1970) Acta rheum. scand., 16, 121 (Effects of osmium tetroxide on the rabbit knee joint nor mal synovial membrane)

Müller, W., Fridrich, R., ANd Pavelka, K. (1974) Therap. Umschau., 31, 483 (Die Synoviorthese mit Yttrium 90)

OKa, M., ReKONEN, A., RUOTSI, A., AND SEPPÄLÄ, U. (1971) Acta rheum. scand., 17, 148 (Intraarticular injection of ${ }^{90} \mathrm{Y}$ resin colloid in the treatment of rheumatoid knee joint effusions)

RuCKeS, J., AND REISSLAND, G. (1960) $Z$. Rheumaforsch., 19, 135 (Untersuchungen über den Gewebsstoffwechsel von Stratum synoviale und Gelenkknorpel des Kniegelenkes beim Kaninchen)

_- Schuckmann, F. (1962) Frankfurt Z. Path., 72, 243 (Über die Topik der Capillaren im Stratum synoviale des Kniegelenkes in Abhängigkeit vom Lebensalter unter besonderer Berücksichtigung der Arthrosis deformans)

SoEuR, R. (1949) J. Bone Jt Surg., 31A, 317 (The synovial membrane of the knee in pathological conditions)

VirkKUNEn, M., KRUSiUs, F.-E., AND HeisKanen, T. (1967) Acta rheum. scand., 13, 81 (Experiences of intra-articular administration of radioactive gold)

VITTALI, H. P. (1970), in 'Knochenerkrankungen, Histologie und Klinik'. Sandoz, Basle

WeBb, F. W. S., Lowe, J., AND Bluestone, R. (1969) Ann. rheum. Dis., 28, 300 (Uptake of colloidal radioactive Yttrium by synovial membrane)

Wiedermann, M., Vykydal, M., PĚGŘímová, E., Pračke, T., AND Valach, V. (1969) Z. Rheumaforsch., 28, 142 (Möglichkeiten der therapeutischen Anwendung von radioaktiven Kolloiden in der Rheumatologie) 